\title{
Acerca de un maestro. Gino Germani, fundador de la sociología en Argentina
}

INÉS IZAGUIRRE

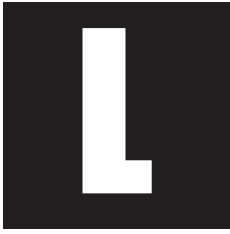

a mayoría de los jóvenes que están estudiando sociología en la Universidad de Buenos Aires y en las demás Universidades argentinas desde hace más de tres décadas, conocen poco de Gino Germani. Lo mismo podría decirse de los profesores, la mayor parte de los cuales no lo conoció, ni lo leyó. Su figura tiene para ellos mucho de mítico -el mito fundacionalpero poco de conocimiento real. Algunos de nosotros hemos tratado de dejar algunas huellas de su paso fundamental por la UBA, como el nombre de nuestro principal Instituto de Investigaciones, y algunos libros que lo recuerdan. Afortunadamente hace pocas semanas apareció en Buenos Aires un bello libro sobre su vida escrito por su hija Ana ${ }^{1}$ que no sólo construye una biografía intelectual y personal riquísima y exhaustiva, sino que la articula con el país perdido, el país que fuimos, y con la historia de nuestra carrera. Como ocurre con muchos acontecimientos y procesos de nuestra vida social, los efectos que sobre la vida universitaria tuvieron las dos últimas dictaduras militares fueron nefastos, y han producido un quiebre, una

\footnotetext{
* Investigadora del Instituto de Investigaciones "Gino Germani" e Profesora Consulta de la Facultad de Ciencias Sociales, UBA - Argentina. Posgraduada en Sociología. Endereço eletrônico: izagui@mail.retina.ar.

1 Ana Alejandra Germani: "Gino Germani. Del antifascismo a la sociología", Buenos Aires, Taurus, 2004.
} 
interrupción de nuestra memoria histórica. La primera, que abarca los años 1966-73, tuvo como objetivo político-militar en sus primeros meses la intervención y/o la ocupación militar de las Universidades nacionales, consideradas como focos subversivos, con la consecuencia de la renuncia de cientos de los mejores docentes, la cesantía de los que se propusieron "resistir desde adentro", entre los que me incluyo, y el exilio de la inmensa mayoría. Claro que, como en esos años Argentina estaba en un proceso de alza de la lucha de masas, las consecuencias se advertirían mucho después. La segunda, que abarca los años 1976-83, es precedida por el breve interregno del gobierno peronista de 1973-76, que arriba al poder apoyado por la izquierda peronista y no peronista y cuyo presidente electo, Cámpora, es obligado a renunciar por la derecha del partido a los 49 días de asumir. A fines de 1975, la guerrilla estaba objetivamente derrotada por las fuerzas armadas legales y los grupos paramilitares, pero la dictadura que le sigue a partir de marzo produce un verdadero genocidio de una fracción importantísima de jóvenes luchadores sociales, producida con la anuencia y/o el silencio cómplice de la dirigencia política de los principales partidos, de los grupos económicos de capital más concentrado y de la "derecha social", esa parte de la población siempre dispuesta a formar en las filas del "partido del orden". ${ }^{2}$ Para darse idea del efecto que esta masacre produjo en las Universidades, es suficiente saber que alrededor del $30 \%{ }^{3}$ de los muertos y desaparecidos de Argentina son universitarios. Tan sólo en nuestra Carrera de la UBA he registrado 60 desaparecidos. No puede asombrar entonces que nuestra comunidad sociológica padezca los efectos de este "agujero social".

\footnotetext{
2 La bibliografía sobre esos años es hoy muy numerosa e importante en Argentina. Sobre el tema de la complicidad, cfr. Izaguirre, Inés "Memorias de guerra. Operativo Independencia", publicado erróneamente con el título "Los primeros pasos de la represión" en Revista Puentes, año 4, no 12, 2004, La Plata, Argentina, Comisión provincial por la Memoria.

3 Este dato está construído sobre una muestra de 11.300 casos de muertos y desaparecidos registrados en mi investigación sobre "El genocidio en la Argentina" hasta el día de la fecha. Digo esto porque permanentemente se agregan nuevos casos a la base de datos, producto de nuevas búsquedas y de nuevos testimonios.
} 
Germani llega de Italia en 1934 como exiliado político, a los 23 años, luego de permanecer preso por antifascista entre 1930 y 1931 en la isla de Ponza, o "del Confine", cuando sólo tenía 19 años. Era hijo de un militante socialista, traía una buena formación en economía, y en Buenos Aires se inscribe como estudiante de filosofía en nuestra querida Facultad de Filosofía y Letras. Allí empieza a funcionar el Instituto de Sociología en 1940, dirigido por Ricardo Levene, ${ }^{4}$ titular de la cátedra de Sociología desde 1918. Levene invita al Instituto como "adscriptos" a personajes muy disímiles: historiadores, filósofos y profesores de sociología de Universidades del interior: Alberto Baldrich, Alfredo Poviña, Raúl Orgaz, Renato Treves (otro italiano perseguido) y Giordano Bruno Genta (nazionalista confeso) del Litoral, a sociólogos reconocidos de Brasil, como Gilberto Freyre, de México, como José Medina Echavarría y de Paraguay, como Justo Prieto. Esta pluralidad era un atisbo débil hasta entonces- de los efectos de la Reforma Universitaria ${ }^{5}$ de 1918, que en realidad llegará a la UBA después de 1955. En el Boletín del Instituto de 1942, encontramos un estudio de Germani sobre la clase media de Buenos Aires, siendo todavía estudiante. Sus brillantes colaboraciones son reconocidas por Levene en las actas del Instituto. Los Boletines, libros de gran calidad material, reflejan la tensión que Germani señalaría más tarde entre los distintos enfoques de la disciplina: especulación versus investigación. En el Boletín de $1943^{6}$ encontramos un anticipo de su futura Estructura social de la Argentina, obra fundacional de lo que Germani consideraba

\footnotetext{
4 En octubre de 1927 se había creado el Instituto de Sociología Argentina, también en Filosofía y Letras, junto con otros institutos que la harían famosa, el de filosofía, el de literatura clásica, el de historia antigua y medieval. Levene le cambió el nombre por el de Instituto de Sociología.

5 La Reforma Universitaria tuvo su epicentro en la Universidad más antigua del país, la Universidad de Córdoba, Argentina, en 1918, como uno de los tantos movimientos de cambio generados por la Revolución socialista de Octubre de 1917 en Rusia. Es un verdadero movimiento revolucionario promovido por los estudiantes, que se sublevan contra la enseñanza clerical, apartada de la ciencia, y que levanta como una bandera la libertad de pensamiento y de cátedra.

6 Los Boletines del Instituto salieron durante 5 números - 1941,1942,1943,1945 y 1947. A partir de ese año, el Instituto queda refundido como una sección del Instituto de Filosofía. Desde 1945, no encontramos colaboraciones de Germani. En 1948 Poviña es designado titular de la cátedra de Sociología y en 1949 es designado su adjunto, Rodolfo Tecera del Franco, peronista fascista convencido a quien tuve como profesor en 1953. En 1952 reaparece el Boletín, perdido completamente el pluralismo que Levene le había impreso.
} 
sociología científica, basada en un uso riguroso de los datos. Se trata de una recopilación, Datos sobre la realidad social argentina entre 1915 y 1942, una síntesis-espejo integral del país de esos años, desde tasas demográficas hasta migraciones, datos económicos de todo tipo, datos sociales sobre conflictos, reuniones sindicales, suicidios, criminalidad, educación, ediciones de libros, etc. Junto a esta confrontación al interior del Instituto en los años previos al peronismo, que se silenciará durante su gobierno, se había desarrollado en Argentina una nutrida producción ensayística cuyos representantes más conspicuos eran Scalabrini Ortiz, Martínez Estrada, Hernández Arregui y Jauretche. Ellos acompañarían en lo político la emergencia del peronismo, coincidente con el reclamo de autoafirmación nacionalista posterior a 1930 de varias burguesías en el capitalismo central: ${ }^{7}$ Alemania, Italia, España, pero también Estados Unidos y Japón. Buceaban en nuestra identidad, ante el poder disolvente de la gran crisis capitalista mundial de los años 30, que nos sumía, como todas las crisis, en la corrupción política y el cambalache social. Fue un movimiento externo a la Universidad, dominada por otras elites, pero donde había grupos que luchaban por construir un proyecto propio de ciencia de alta calidad, sobre todo en medicina, como la Escuela de Fisiología de Bernardo Houssay o el Instituto de Patología Regional de Salvador Mazza. La guerra mundial había hecho posible el crecimiento de los países de la periferia, que quedaron protegidos de los centros imperiales. El fin de la guerra marca la emergencia del peronismo en Argentina, acaudillado por un coronel que venía de dar un golpe nacionalista el 4 de junio del 43, representando a una fracción burguesa con un proyecto de desarrollo industrial, hasta ese momento más encarnado en el

\footnotetext{
7 En lo económico, el sustento teórico de esa autoafirmación de las burguesías nacionales, provino de un lord inglés (Keynes). En lo político en esos países se desarrollaron diversas variantes del nacionalismo y del socialismo autoritarios, mixtura ideológica de consecuencias trágicas que ha sido poco estudiada, entre otras razones porque en el campo de la izquierda, dominado durante décadas por el estalinismo, de eso no se habla.
} 
ejército que en la sociedad civil. Triunfaba en Argentina el proyecto que acababa de ser derrotado en el mundo desarrollado por las mismas burguesías liberales que nos habían asignado con éxito el papel de proveedores de alimentos. La lucha entre ambas fracciones de burguesía se resolvió en Argentina con el golpe del 43. Las masas de trabajadores migrantes atraídos a la industria durante la guerra, apoyaban el proyecto de Perón, pero no necesariamente el contenido ideológico fascista desarrollado por las burguesías en los países del Eje, y sustentado por la fracción militar que había triunfado en el golpe. ${ }^{8}$ La lucha ideológica entre fascismo y liberalismo se trasladó a la Argentina sin matices, y se dio con virulencia tanto entre las capas ilustradas, como entre los viejos obreros industriales de izquierda y los nuevos obreros migrantes. Se expresó con fuerza en la Universidad, donde la mayoría de los profesores comunistas y antifascistas debieron exiliarse o dedicarse a otras actividades: el país receptor fue en casi todos los casos Estados Unidos, pues Europa estaba destruída. ${ }^{9}$ La barbarie que había arrasado a Europa impidió al fin de la guerra distinguir las diferencias entre el tipo de alianza de clases que expresaba el peronismo, con la presencia dominante de la clase obrera, y los fascismos europeos, asentados en las clases medias, del mismo modo que invisibilizaba el enfrentamiento entre capitalismo y comunismo, presente en la disputa por los territorios de Europa del Este y de Alemania, que encarnaría como maccarthysmo en Estados Unidos y se trasladaría al mundo como guerra fría. Quizás porque la

\footnotetext{
8 El apoyo innegable de Perón y su gobierno a los dirigentes nazis que lograron huir de Alemania ha sido verificado por la Comisión de Esclarecimiento de las Actividades Nazis en la Argentina (CEANA), quien ubicó la documentación que prueba la existencia del SARE, Sociedad Argentina de Recepción de Europeos, fundada por Perón y por Rodolfo Freude a fines de la guerra, y que funcionaba en la Casa de gobierno. Dicha Sociedad organizó a través de la Dirección de Migraciones la llegada y recepción de no menos de 180 criminales de guerra. (Cfr. Diario Página 12, del 14/6/2000, pág.6). No obstante, también el gobierno de Perón fue uno de los primeros del mundo en reconocer al Estado de Israel en 1948, y mantuvo siempre excelentes relaciones con la DAIA.

9 Entre los argentinos más conocidos, se exiliaron Risieri Frondizi, Rolando García, Oscar Varsavsky y Manuel Sadosky. Los europeos que habían huído del fascismo permanecieron en el país (Angel Garma, Mimi Langer, Gino Germani, Rodolfo Mondolfo, Renato Treves) aunque fuera de la Universidad.
} 
búsqueda de libertad lo había obsesionado desde su adolescencia, Germani supo ver esa diferencia en el peronismo: escribió sobre el contenido liberador de la legislación peronista para el obrero y el militante sindical frente a los patrones, a diferencia de lo que ocurría con las capas medias y sus fracciones ilustradas. Era un científico con vocación de objetividad. Una anécdota contada por el Prof. Eduardo J. Prieto, contemporáneo de Germani, lo pinta de cuerpo entero. ${ }^{10}$ En 1941, Prieto era presidente del Centro de Estudiantes de Filosofía y Letras, y Germani, miembro del Centro, era militante antifascista y socialista. Cuando la invasión de la URSS por Hitler, que prueba la falacia del pacto Hitler-Stalin, muchos militantes del Centro intentan echar a los comunistas, y hasta se producen escenas de pugilato. Germani, muy respetado entre sus compañeros, advierte que no era momento de dividirse, y que los jóvenes comunistas del centro no tenían la culpa de los enjuagues políticos de Stalin. Mantiene así la unidad. Por entonces estudiaba sociología en la rica Biblioteca de la Casa del Pueblo, sede del partido Socialista, donde leía desde los clásicos europeos hasta los empiristas norteamericanos, y además los libros"se los prestaban por un mes, y no por una semana, como en la Facultad". Años después, la política de Perón se ensañaría con la Universidad y también con la Casa del Pueblo. No sólo la policía nos pedía la Libreta Universitaria al entrar a la Facultad, -yo era estudiante de filosofía en los 50- sino que las humanidades quedaron en manos de las fracciones católicas más retardatarias. Esa ofensa a la inteligencia nunca se restañó del todo: yo estuve en la fila de estudiantes que, en el hall de entrada de Filosofía y Letras sacó literalmente a empujones de su despacho en septiembre del 55 al decano Serrano Redonnet. A partir de 1955 todo cambió en Filosofía y Letras. ${ }^{11}$ Pasábamos la mayor parte del tiempo en la Facultad: volvían los profesores del exilio, íbamos a todas sus clases, se hacían asambleas, volvía-

10 Eduardo J. Prieto era un notable profesor de filología latina en la Facultad de Filosofía y Letras. Sus relatos sobre Germani, así como los de Elena Chiozza, geógrafa reconocida coetánea de ambos, realizados en una entrevista efectuada en 1999 por Ana Germani, son imperdibles.

11 Tengo claro que una gran parte de la sociedad argentina, particularmente la clase obrera, simultáneamente la estaba pasando muy mal, reprimida y perseguida junto con la militancia peronista. 
mos a leer autores prohibidos. Ya en 1957, los estudiantes de filosofía nos enteramos de que en un edificio cercano se estaban dictando las primeras materias de las nuevas Carreras: Sociología, Antropología, Psicología, Ciencias de la Educación. Comencé a asistir a las fascinantes clases de Germani, informales, sin saco ni corbata, que llenaba el pizarrón de datos, y nos abría la cabeza a la historia del mundo. Yo me gradué en filosofía en febrero de 1959. En marzo se abrieron concursos de ayudantes de sociología y en julio ya estaba designada. Ese mismo año se creó el CONICET y obtuve mi primera beca. Germani fue desde entonces mi director. Recuerdo que en los primeros años 60 trajeron al Instituto la IBM 101, la primera computadora de la Facultad, grande como un escritorio, y que aprendimos a manejar con un profesor de Exactas. Los "Cuadros" se preparaban en un tablero enorme, lleno de cables y enchufes. Al mismo tiempo los graduados cursábamos el posgrado en sociología. Recuerdo como si fuera hoy cuando, con los datos del Censo Universitario de 1960 hice un enorme cuadro sobre el origen de los padres y abuelos de los estudiantes, por Facultad. Era la primera vez que intentaba construir un cuadro significativo de tres variables, como aprendíamos en Metodología. Era una "sábana" y yo no lograba descifrarlo. Pero lo había hecho con todas las reglas del arte y se lo llevé a Germani a su escritorio, siempre abierto para recibirnos. "Es extraordinario!" me dijo. "Fíjese". Me mostró cómo había que leer el cuadro y todo lo que decía del país: el 50\% de los estudiantes era hijo de inmigrantes, la mayor proporción de clases altas estaba en Derecho, Arquitectura y Exactas, etc. Estaba contento por mis hallazgos, que yo misma no veía, y eso le había borrado el gesto hosco que solía tener. ¿Cómo evalúo hoy aquel momento fundacional? Sólo tengo palabras de elogio y de afecto: se hizo tanto, en tan poco tiempo, con tanto entusiasmo, todos con "la camiseta de la Carrera", con un nivel de politización altísimo de estudiantes y profesores, sin "obedientes" de partido. Cada hecho político era intensamente vivido. Hoy 
pienso que Germani debe haber sufrido mucho, porque era acusado a menudo por los alumnos de ser "pro-yanqui", por enseñar autores funcionalistas y por haber obtenido un importante subsidio Ford, con el cual no sólo organizó la muestra y la encuesta de Estratificación más importante del Gran Buenos Aires que se haya hecho nunca, simultánea con Montevideo, Santiago de Chile y Río de Janeiro, sino también la mayor Biblioteca de Ciencias Sociales de América Latina, destruída luego por las dictaduras. Pero eso lo vi mucho después. En esos pocos años Germani viajaba incansablemente: Vinculó a nuestro Departamento y a nuestro Instituto con la Asociación Internacional de Sociología, y fué co-fundador y concurrió a todos los Congresos del ALAS, la Asociación Latinoamericana de Sociología. Las primeras, y únicas, Jornadas Latinoamericanas de Sociología de Argentina las organizó Germani en 1961, en el Nacional Buenos Aires. A ellas vinieron todos los latinoamericanos famosos: Desde Pablo González Casanova hasta Fernando Henrique Cardoso y Enzo Faletto, pasando por Ruy Mauro Marini y el cura guerrillero, Camilio Torres. Germani instaló, en Argentina antes que en Europa, la sociología científica. En 1964, a poco de graduarse las primeras camadas, Germani dejó la dirección de la Carrera y del Instituto y se instaló en el Di Tella. Duraría poco allí, pues antes del derrocamiento de Illia se fué a Harvard, que lo recibió con el respeto que se debe a los grandes, aunque no tenía título de doctor, ni concurso. Con gran dolor, como recuerda su hija, al punto que en su casa no permitía que se hablara inglés. Creo que Sociología todavía conserva en sus viejos profesores, y en muchos de sus jóvenes investigadores, algo de aquel espíritu.

Recorriendo la vida de Germani descubro algo que seguramente nos ha pasado a todos los que lo conocimos: Germani valoró la democracia mucho antes que se pusiera de moda entre nosotros, y movido por los mismos problemas: la dictadura, la guerra, el orden policíaco y el deseo de libertad. Pero tuvo la fineza intelectual y la capacidad política de establecer las dife- 
rencias entre regímenes nacionalistas de los que fue contemporáneo y que su pasión vital rechazaba: el nazismo alemán, el fascismo italiano, el franquismo español, del peronismo argentino, $y$, particularmente en este último, la inteligencia de señalar las diferencias sociales que impedían la generalización del maniqueísmo político con que la pequeña burguesía ilustrada describía la sociedad argentina en su época.

Del mismo modo valoró la libertad, y en su tarea, la libertad académica. En la Universidad aplicó la Reforma, nuestra Reforma latinoamericana en Buenos Aires. Y lo hizo junto a los reformistas más consecuentes. Para quien como yo conoció y estudió en la Universidad de los primeros años 50, dominada por la derecha católica, cuando Perón le había cedido la educación y la Universidad a la Iglesia, el aire fresco que significó ese cambio en la vida académica es indescriptible. El mismo lo dice con precisión en el prefacio a "El miedo a la libertad" de E.Fromm: "Toda idea tiene derecho a ser expresada, porque cada una lleva en sí misma una parte de la realidad". Esa realidad que es argamasa de muchas síntesis de contrarios, de los cuales no podemos prescindir, aunque no nos gusten, sin deformarla. El tercer punto que necesito destacar en la obra de Germani es que nos enseñó a investigar. Para quienes siguen confundiendo al opinador con el investigador, debo decir que, casi sin saber cómo, fuimos incorporando trabajosamente las condiciones de un proceso que va de menos conocimiento a más conocimiento. Germani luchó por instalar ese proceso en nosotros. Y lo logró. Quizás no es lo que él pensó, o soñó, pero esta distancia existe siempre. En cambio todas las personas que él formó siguieron trabajando, investigando, y pasada la catástrofe, de nuevo enseñando. Las grandes confrontaciones de la sociedad argentina también se expresaron entre nosotros. Tan sólo en nuestra Carrera hubo 60 muertos y desaparecidos. Afortunadamente en la Carrera hoy está presente toda aquella diversidad. Es muy posible que no podamos reivindicar aquella calidad. Pero de nuevo, 
esa distancia existe siempre.

Quizás seamos hoy mucho más escépticos acerca de las perspectivas de una sociología como ciencia estricta. Hasta los sociólogos se llaman a sí mismos "cientistas", cocoliche académico que mezcla la mala traducción del social scientist, con el remedo del técnico del saber práctico que arregla las caries. Hoy sabemos que la objetividad pura no es posible, y que nuestros datos son construcciones teórico-empíricas, y que nuestras miradas se enmarcan siempre desde un lugar, en un tiempo histórico. Pero la objetividad sigue siendo una meta: objetivar es transformar en objeto, visibilizar. Es también un proceso. Un proceso de madurez, de descentramiento. Lo que quizás nos ha hecho más escépticos es que transitamos un tiempo donde los poderes se han hecho muy visibles y se han mostrado en toda su fuerza acumulada, mucho más grandes, poderosos y fuertes que lo que se percibía en tiempos de Germani.

En este punto debo confesar que, leyendo el libro de Ana, su hija, me sorprendió advertir la dimensión humana -vulnerable- de Germani quizás un poco ingenua, esperanzada, re-negadora del fuerte maccarthysmo norteamericano que operaba al interior y al exterior de ese país, en plena guerra fría a fines de los 50 y comienzos de los 60, - para cuyas autoridades Germani era un subversivo- a la inversa de como se lo consideraba en Argentina, pero que él no atribuía a una política discriminadora de EEUU, sino al celo excesivo y equivocado de algunos funcionarios de migraciones. El relato acerca de sus avatares para obtener la "visa" que le permitiera viajar a ese país no lograba mellar su confianza en el mito del gran país democrático, respetuoso de la ley. Como supimos mucho después, ya desde 1950 todos los años cientos de militares latinoamericanos- entre ellos los argentinos- concurrían a las escuelas norteamericanas de instrucción, para aprender las técnicas de intervención en sus propios países. Importaron también de los generales franceses que actuaron en la guerra de Argelia, 
simultáneamente con las fuerzas armadas de Argentina, la tecnología francesa del interrogatorio y la tortura que aplicaron generosamente en Vietnam, y que se aplicaría en Argentina. También supimos hace muy poco del aval que el Departamento de Estado en la figura de Kissinger le dio a la dictadura genocida. Aún hoy no sabemos bien dónde quedaron todos los libros arrancados de los estantes de la gran Biblioteca de Sociología de los años 60 y 70 y nos cuesta un enorme esfuerzo reconstruir la historia. Como efecto de esa tierra arrasada se hundió en el olvido y la confusión toda la historia fundacional de nuestra Carrera, incluído Germani.

Sin embargo no pudieron con nosotros, ni siquiera dos dictaduras. Por lo cual yo diría que Germani, el "tano", ganó. Su obcecación nos enseñó a investigar, a ser rigurosos, a fundamentar con datos nuestras afirmaciones, y la realidad, no él, nos obligó a ser menos intolerantes. Y si hemos aprendido que no podemos hacer la revolución con la sociología, también sabemos hoy que no hay nada más revolucionario que el conocimiento verdadero. 


\section{Resumen}

Este artículo sintetiza algunos aspectos de la vida académica e intelectual de Gino Germani, Ilegado a la Argentina desde Italia en 1934, perseguido por el fascismo y fallecido en Roma en 1978, fundador de la carrera de sociología y de la sociología científica en Argentina, y maestro de muchos de quienes hoy todavía la enseñamos en la Universidad de Buenos Aires. Hemos tratado de dejar algunas huellas de su paso fundamental por la UBA en los años 60, como el nombre de nuestro principal Instituto de Investigaciones, y algunos libros que lo recuerdan. Sin embargo, Germani no es muy conocido entre los estudiantes ni entre los profesores más jóvenes. Como ocurre con muchos acontecimientos y procesos de nuestra vida social, los efectos que sobre la vida universitaria tuvieron las dos últimas dictaduras militares fueron nefastos, y han producido un quiebre, una interrupción de nuestra memoria histórica. En este trabajo se destaca la intensidad de la labor de Germani como sociólogo, la pasión que puso en su tarea y la conducta ética que presidió su vida, que trató de analizar con objetividad los procesos políticos y sociales de una época de gran riqueza de ideas y de esperanzas. Mientras estamos tratando de dejar atrás las lacras del neoliberalismo de mercado en la sociedad, éste sigue agazapado en muchas instituciones, y la Universidad de Buenos Aires es una de ellas. Es momento de que los científicos sociales recuperemos el ejercicio ético de nuestra profesión, denunciando y enfrentando, como lo hiciera Germani con su ejemplo de vida, la impunidad que se encarna en el orden social.

Palabras-clave: sociología científica, antifascismo, conducta ética. 
INTERFACES

INTERFACES

\section{About a master: Gino Germani, founder of sociology in Argentina}

\section{Inés Izaguirre}

This article summarizes some aspects of the academic and intellectual life of Gino Germani, who arrived in Argentina from Italy in 1934, persecuted by Fascism, and died in Rome in 1978. He was the founder of the sociology career and scientific sociology in Argentina, as well as the master of many of us who teach at the University of Buenos Aires (UBA). We have managed to leave some marks of his fundamental passage through UBA in the 1960s, such as the name of the main Institute of Inquiries and some books that remember him. Nevertheless, Germani is not widely known among students and younger professors. As is the case with several events and processes in our social life, the effects of the two last military dictatorships over university life were disgraceful and produced a breakdown, an interruption of our historical memory. This work stresses the strength of Germani's work as a sociologist, the passion he put on his task, and the ethical conduct that marked his life, which objectively examined the political and social processes of a time of great wealth of ideas and hopes. While we work to leave behind the scars of market neoliberalism in society, it is still embedded in several institutions, and the University of Buenos Aires is one of them. It is time for us social scientists regain the ethical exercise of our profession, denouncing and confronting impunity incarnated in social life, as did Germani through the example of his life.

Key words: scientific sociology, anti-fascism, ethical conduct 